\title{
EVALUATION OF A GLOBAL SNOW DEPTH ANALYSIS BASED ON OPTIMAL INTERPOLATION
}

\author{
Cezar Kongoli ${ }^{12}$, Tomas Smith ${ }^{2}$ \\ ${ }^{1}$ Earth System Science Interdisciplinary Center (ESSIC), University of Maryland College Park, USA; \\ ${ }^{2}$ NOAA/National Environmental Satellite and Data Information Service (NESDIS), College Park, MD, USA; \\ "Corresponding Author Cezar Kongoli, e-mail: cezar.kongoli@noaa.gov;
}

Received May 2019; Accepted July 2019; Published December 2019;

DOI: https://doi.org/10.31407/ijees9430

\begin{abstract}
Assimilation of snowpack observations into Numerical Weather Prediction (NWP) models represents a key component that impacts the accuracy of predicted meteorological parameters. NOAA's National Centers for Environmental Prediction (NCEP) operational NWP models routinely assimilate observations of snow depth and snow cover area to improve snow model initializations. A new snow depth analysis based on optimal interpolation method has been developed with improved spatial resolution compared to the existing analysis and the capability to assimilate both satellite and station snow depth. An essential component and assumption of the analysis are the spatial correlation functions and scales of snow depth distribution with respect to horizontal distance and elevation. Based on these correlation functions and the predetermined data errors, snow depth from the surrounding stations are weighted to compute an analysis snow depth estimate. This study presents an accuracy assessment of the analysis over North America that uses correlation scales currently adopted in operational snow analysis at world's major weather and climate prediction centers: an e-folding scale of $120 \mathrm{~km}$ for horizontal distance and an e-folding scale of $800 \mathrm{~m}$ for elevation. Snow depth data to drive and evaluate the analysis are obtained from the Global Historical Climatology Network (GHCN) during the 2016-2017 winter season. Snow depth from NOAA's Global Forecast System (GFS) was used as first guess. It was found that a range of $600 \mathrm{~km}$ is sufficient for a near complete coverage of analysis over North America in areas with sparse in-situ measurements available for interpolation. The analysis improves first guess estimates substantially over relatively flat areas. However, improvements are smaller, and the accuracy is much lower over high-elevation terrain, mainly attributed to inaccurate e-folding scales used for interpolation.
\end{abstract}

Key words: evaluation, global snow depth, analysis optimal interpolation, NOAA 